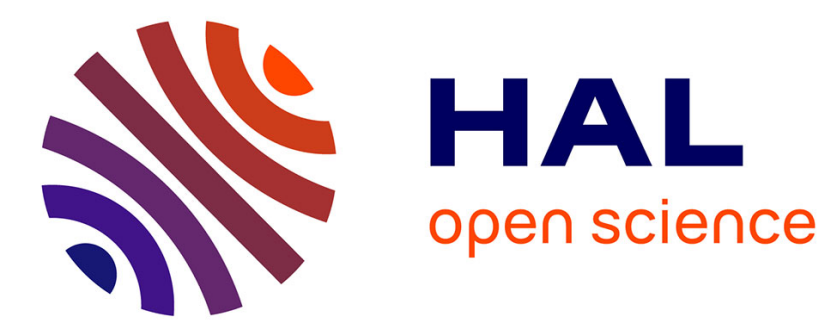

\title{
Dissipative and microstructural effects associated with fatigue crack initiation on an Armco iron
}

Chen Wang, Antoine Blanche, Danièle Wagner, André Chrysochoos, Claude Bathias

\section{- To cite this version:}

Chen Wang, Antoine Blanche, Danièle Wagner, André Chrysochoos, Claude Bathias. Dissipative and microstructural effects associated with fatigue crack initiation on an Armco iron. International Journal of Fatigue, 2013, 58, pp.152-157. 10.1016/j.ijfatigue.2013.02.009 hal-00832474

\section{HAL Id: hal-00832474 https://hal.science/hal-00832474}

Submitted on 24 Mar 2016

HAL is a multi-disciplinary open access archive for the deposit and dissemination of scientific research documents, whether they are published or not. The documents may come from teaching and research institutions in France or abroad, or from public or private research centers.
L'archive ouverte pluridisciplinaire HAL, est destinée au dépôt et à la diffusion de documents scientifiques de niveau recherche, publiés ou non, émanant des établissements d'enseignement et de recherche français ou étrangers, des laboratoires publics ou privés. 


\title{
Dissipative and microstructural effects associated with fatigue crack initiation on an Armco iron
}

\author{
C. Wang ${ }^{a}$, A. Blanche ${ }^{\text {b }}$, D. Wagner ${ }^{\text {a,* }}$, A. Chrysochoos ${ }^{\text {b }}$, C. Bathias ${ }^{\text {a }}$ \\ ${ }^{a}$ University Paris Ouest Nanterre, LEME Laboratory, 50 Rue de Sèvres, 92410 Ville D'Avray, France \\ ${ }^{\mathrm{b}}$ University Montpellier 2, LMGC Laboratory, CNRS, Place Eugène Bataillon, 34095 Montpellier, France
}

\begin{abstract}
In this study, the first signs of fatigue crack initiation are studied in the HCF domain on a body centered cubic Armco iron (with 80 ppm of carbon content). Some tests are performed on plate specimens through a piezoelectric fatigue machine. During fatigue tests, the deformation evolution is observed by optical microscope, and the temperature recording on the specimen surface is achieved by an infrared focal plane array camera. From the temperature recording, the intrinsic dissipation field is calculated using a local expression of the heat diffusion equation. The results show that above a given stress level, Slips Marks can be clearly observed on the surface specimen, and related to the intrinsic dissipation distribution. Observations through a Scanning Electron Microscope on the specimen surface and the fracture surface are related to stage I and stage II of fatigue damage.
\end{abstract}

Keywords

Armco iron; Fatigue crack initiation; Infrared thermography; Intrinsic dissipation; Persistent Slips Bands

\section{Introduction}

The fatigue crack mechanism consists in an initiation crack stage (stage I) and a propagation stage (stage II). For materials without inclusions with a single phase, the first damage events in the stage I are due to the occurrence of Slips Marks (SMs) on the specimen surface $[1,2]$. In fcc materials these SMs are called Persistent Slips Bands (PSBs), with a particular dislocation structure beneath the PSB [3]. In bcc materials (Armco iron), the identification of these SMs with PSBs is matter for debate [3-8]. The reason lies in the very different temperature and strain rate dependent dislocation glide behavior in bcc metals, as compared to fcc metals. Moderate increase of temperature, low cyclic strain rates and alloying by substitutional atoms (e.g. in $\mathrm{Fe}-\mathrm{Si}$ ) and interstitial atoms (e.g. $\mathrm{C}$ and $\mathrm{N}$ in $\alpha$-iron) make the dislocation glide modes of bcc metals more similar to those of fcc metals and, then, PSBs may be observed.

The beginning of the crack propagation stage with striations occurrence (stage II) has been previously studied by the temperature recording on the specimen surface during the test $[9,10]$, which allows the determination of the number of loading cycles at crack initiation.

In this paper, from the temperature recording on the specimen surface of an Armco iron during fatigue tests, the intrinsic dissipation distribution on the specimen surface is calculated using a local

\footnotetext{
* Corresponding author. Tel.: +331409757 76; fax: +33147974878

E-mail address: daniele.wagner@u-paris10.fr (D. Wagner).
}

expression of the heat diffusion equation. Besides, fractographic observations are performed on the specimen surface and fracture surface, and correlated to the intrinsic dissipation field.

\section{Material}

The studied material is a polycrystalline $\alpha$ iron whose chemical composition is given in Table 1 . The carbon content is $80 \mathrm{ppm}$. The microstructure is ferrite with equiaxe grains. The inclusion size is less than $1.5 \mu \mathrm{m}$. The ferrite grain size ranges from 10 to $40 \mu \mathrm{m}$. No specifically orientation is observed by EBSD. Yield Stress is $240 \mathrm{MPa}$ and Ultimate Tensile Stress is $300 \mathrm{MPa}$.

\section{Experimental procedure}

\subsection{Mechanical and thermal procedure}

Tests are performed on a piezoelectric fatigue machine designed by Bathias and Paris, [11]. An infrared camera was used to record the temperature evolution during the test.

For the surface observation condition by IR camera, a $1 \mathrm{~mm}$ thickness flat specimen (Fig. 1) is used to carry out fatigue tests. Specimen, special attachment and piezoelectric fatigue machine constitute the resonance system working at $20 \mathrm{kHz}$. The cyclic loading is tension-compression, and the stress ratio is $R_{\sigma}=-1$.

Before testing, both surface sides of the flat specimen are polished until the roughness less than R0.2. One side surface of the flat 
Table 1

Chemical composition of studied material (mass\%).

\begin{tabular}{|c|c|c|c|c|c|c|c|c|c|c|}
\hline$C$ & $\mathrm{P}$ & $\mathrm{Si}$ & Mn & $S$ & $\mathrm{Cr}$ & $\mathrm{Ni}$ & Mo & $\mathrm{Cu}$ & Sn & $\mathrm{Fe}$ \\
\hline 0.008 & 0.007 & 0.005 & 0.048 & 0.003 & 0.015 & 0.014 & 0.009 & 0.001 & 0.002 & Balance \\
\hline
\end{tabular}

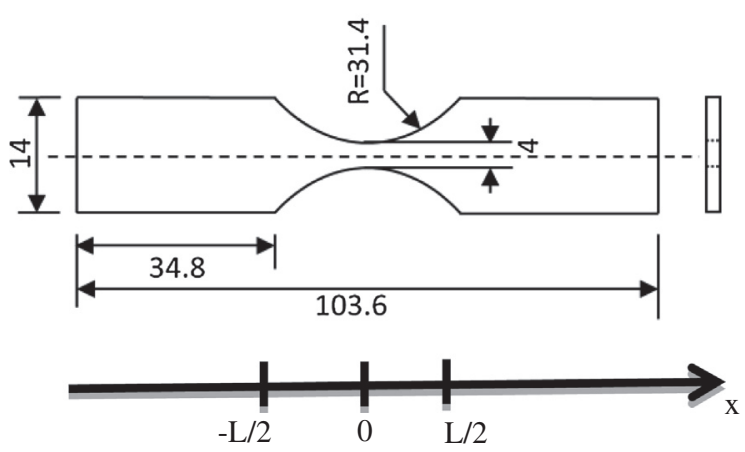

Fig. 1. Design of flat specimen (unit: $\mathrm{mm}$ ).

specimen is etched and another side painted in black color to have the surface emissivity close to 1 .

From the temperature measurements, the intrinsic dissipation is determined using a 2D thermal model (see Section 4).

\subsection{Tests}

Fatigue tests are periodically interrupted, and the stress level is increased until the specimen fracture is obtained. For the sample reported here, the test is conducted as is described in Table 2.

During the last run (test 5) with a stress of $120 \mathrm{MPa}$, the specimen broke.

\section{Determination of intrinsic dissipation}

Concepts and results of the thermodynamics of irreversible processes must be used to define the different heat sources induced by fatigue processes. Thermodynamics with internal state variables has been used (and more precisely the Generalized Standard Materials formalism [12]). Combining the local expressions of the first and second principles of thermodynamics leads to the heat diffusion equation:

$$
\begin{aligned}
\rho C \dot{T}-\operatorname{div}(\operatorname{kgrad} T) & =\sigma: \dot{\varepsilon}-\rho \psi_{, \varepsilon}: \dot{\varepsilon}-\rho \psi_{, \alpha} \cdot \dot{\alpha}+\rho T \psi_{, \varepsilon T} \\
& : \dot{\varepsilon}+\rho T \psi_{, \alpha T}: \dot{\alpha}+r_{e}
\end{aligned}
$$

where $\rho$ denotes the mass density, $C$ the specific heat, $k$ the heat conduction tensor, $\sigma$ the Cauchy stress tensor, $\varepsilon$ the strain tensor with $\dot{\varepsilon}$ the strain rate tensor, $\alpha$ a vector of internal state variables. The left-hand side consists of a differential operator applied to the temperature, whereas the right-hand side gathers the various types of heat sources: the intrinsic dissipation $d_{1}=\sigma: \dot{\varepsilon}-\rho \psi_{, \varepsilon}$ :

Table 2

Fatigue tests.

\begin{tabular}{lll}
\hline Test & Number of cycles & Stress $\sigma_{\mathrm{a}}(\mathrm{MPa})$ \\
\hline Test 1 & $10^{7}$ & 80 \\
Test 2 & $10^{7}$ & 90 \\
Test 3 & $10^{7}$ & 100 \\
Test 4 & $10^{7}$ & 110 \\
Test 5 & $5 \times 10^{6}$ & 120 \\
\hline
\end{tabular}

$\dot{\varepsilon}-\rho \psi_{, \alpha} \cdot \dot{\alpha}$, the thermo-mechanical coupling sources $S_{\text {the }}=$ $\rho T \psi_{, \varepsilon T}: \dot{\varepsilon}+\rho T \psi_{, \alpha T}: \dot{\alpha}$, and a possible external heat supply $r_{\mathrm{e}}$ (e.g. radiation exchanges). The intrinsic dissipation characterizes the material degradation accompanying the irreversible transformation of the microstructure, whereas the thermomechanical heat sources translate the thermo-sensitivity of the matter, indicating that the mechanical and thermal states are closely coupled. In the case of metallic materials, when no first order solid-solid phase change occurs [13], the thermomechanical coupling mechanisms are limited to thermoelastic effects. In the following, the thermoelastic source is called $s_{\text {the }}$.

Note that the heat diffusion equation is a partial differential equation applied to temperature. Estimating the left hand member using the thermal data then leads to an overall estimate of the different heat sources grouped in the right hand side. Note also that each differential operator is weighted by material parameters such as $\rho, C$ and $k$. So, whatever the method used to determine the heat source field, the reliability of results depends not only on the accuracy of the temperature measurements [14] but also on the knowledge of the material parameters [15]. Up to now, the following strong hypotheses have been put forward during the infrared image processing to compute the heat sources [16]:

(a) Mass density and specific heat are material constants, independent of the thermodynamic state.

(b) The heat conduction tensor remains constant and isotropic during the test $\left(k_{\mathrm{ij}}=k \cdot \delta_{\mathrm{ij}}\right)$

(c) The external heat supply $r_{\mathrm{e}}$ due to heat exchange by radiation is time-independent, so the equilibrium temperature field $T_{0}$ verifies $-\Delta T_{0}=r_{\mathrm{e}}$. It is then convenient to consider the temperature variation $\theta$ defined by $\theta=T-T_{0}$.

Taking into account these hypotheses, the heat equation can be rewritten in the following compact form:

$\rho C \dot{\theta}-k \Delta \theta=d_{1}+S_{\text {the }}$

By integrating Eq. (2) over the thickness and after showing that the measured surface thermal map is very close to the depth-wise averaged temperature field $\theta(x, y, t)$ [17], the following equation can be obtained:

$\left.\rho C\left(\frac{\partial \bar{\theta}}{\partial t}+\frac{\bar{\theta}}{\tau_{t h}^{2 \mathrm{D}}}\right)-k \frac{\partial^{2} \bar{\theta}}{\partial x^{2}}+\frac{\partial \bar{\theta}}{\partial y^{2}}\right)=\bar{d}_{1}+\bar{S}_{\text {the }}$

where $\bar{\theta}(t, x, t), \bar{d}_{1}(t, x, y)$ and $\bar{S}_{\text {the }}(t, x, t)$ are the mean depth-wise temperature, dissipation and thermoelastic source, respectively. The parameter $\tau_{t h}^{2 \mathrm{D}}$ acts as a time constant characterizing the perpendicular heat exchanges (by convection and radiation) between front and back specimen faces and the surroundings. The heat exchanges are supposed linear with respect to the temperature variation. This 2D-approach has already been widely detailed and successfully used to track localization zones during monotonic tensile tests [18].

Taking into account the loading frequency $(20 \mathrm{kHz})$ and the maximum frame rate of the IR camera $(100 \mathrm{~Hz})$, the periodic thermoelastic sources are in this situation out of reach. Moreover, if the variations of the thermoelastic physical parameters induced by fatigue mechanisms over a loading cycle can be neglected, the mean 


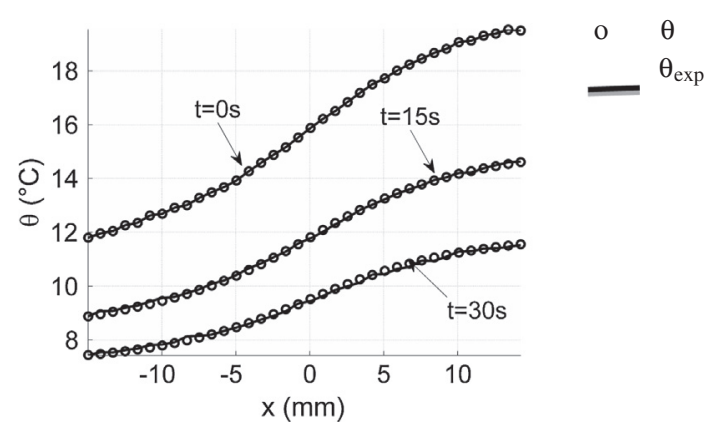

Fig. 2. Expermental and predicted results.

thermoelastic source per cycle vanishes, leaving alone the mean dissipation per cycle.

The last stage is to compute the intrinsic dissipation $d_{1}$ estimating the different partial derivative operators, using discrete noisy thermosignals. Local spatiotemporal fitting is used to approximate the temperature field by this function:

$\theta^{a p p}=P_{1}(x, y) t+P_{2}(x, y)$

where $P_{1}(x, y)$ and $P_{2}(x, y)$ are second-order polynomials in $x$ and $y$. These polynomials are finally identified using the least-squares method and then used to compute the intrinsic dissipation. The reader interested in the image processing method is referred to [18].

To show the relevance of the 1D or 2D thermal modeling, thermal returns are studied. In such a situation, no heat sources occur and a pure diffusion problem can be analyzed. For 1D analysis [19], the partial differential problem is sum up in Eq. (5) where $\theta \exp \left(x= \pm \frac{L}{2}, t\right)$ is the measured Dirichlet boundary conditions, $L$ being the length of the sample gage part (see Fig. 1):

$\left.\rho C\left(\frac{\partial \theta^{=}}{\partial t}+\frac{\theta^{=}}{\tau_{\text {th }}^{1 \mathrm{D}}}\right)-k \frac{\partial^{2} \theta^{=}}{\partial x^{2}}+\frac{\partial \theta^{=}}{\partial x} \frac{S^{\prime}}{S}\right)=d_{1}^{=}+S_{\text {the }}^{=}$

With the following limit conditions: $\theta^{=}(x, t=0)=\theta^{=} \exp (x, t=0)$

$\theta=\left(x= \pm \frac{L}{2}, t\right)=\theta^{=} \exp \left(x= \pm \frac{L}{2}, t\right)$

Fig. 2 shows different temperature profiles. The dissymmetry of boundary conditions comes from the fact that, at one extremity, the sample is fixed at the horn $(x=-L / 2)$ which is cooled by a cold

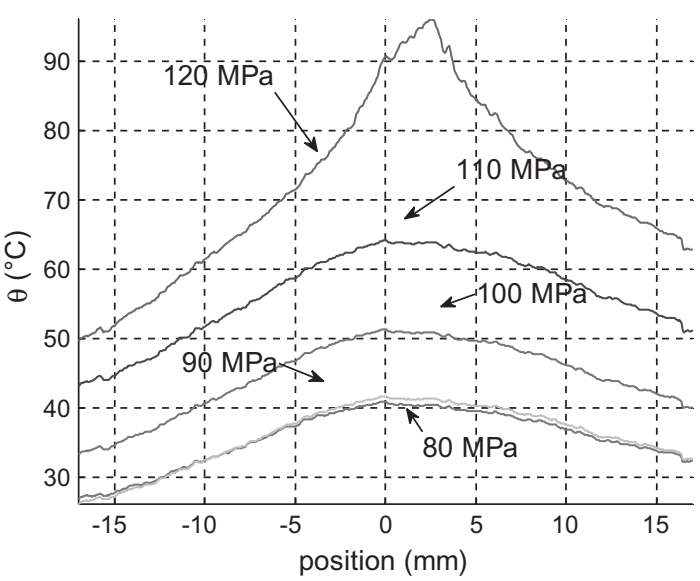

Fig. 4. Temperature evolution along the length of specimen.

air jet, while the sample is totally free on the other side $(x=L / 2)$. The comparison between assessments and results derived from Eq. (6) are once more satisfactory.

\section{Results and discussion}

\subsection{Thermal results}

Fig. 3 shows the temperature recordings (for the different applied stresses) against the number of loading cycles. As is reported in Ref. [9], the temperature has a sharp increase at the beginning of the test and tends progressively towards an asymptote if there is no crack. Higher is the stress, higher is the temperature level.

If no crack appears, the highest temperature is always found close to the cross-section in the middle of the specimen, in correspondence to the highest stress distribution. Fig. 4 shows the temperature evolution along the specimen length (for the different applied stresses). Due to the horn (metallic component which increases the conduction phenomenon), the temperature profile is not symmetric. The top of the specimen (near the horn) is colder than the specimen bottom.

When the specimen is tested at higher stress, the crack takes place. Fig. 5 shows infrared thermal images corresponding to different numbers of cycles.

The intrinsic dissipation fields on the specimen surface are shown in Fig. 5. The abscissa corresponds to the specimen width

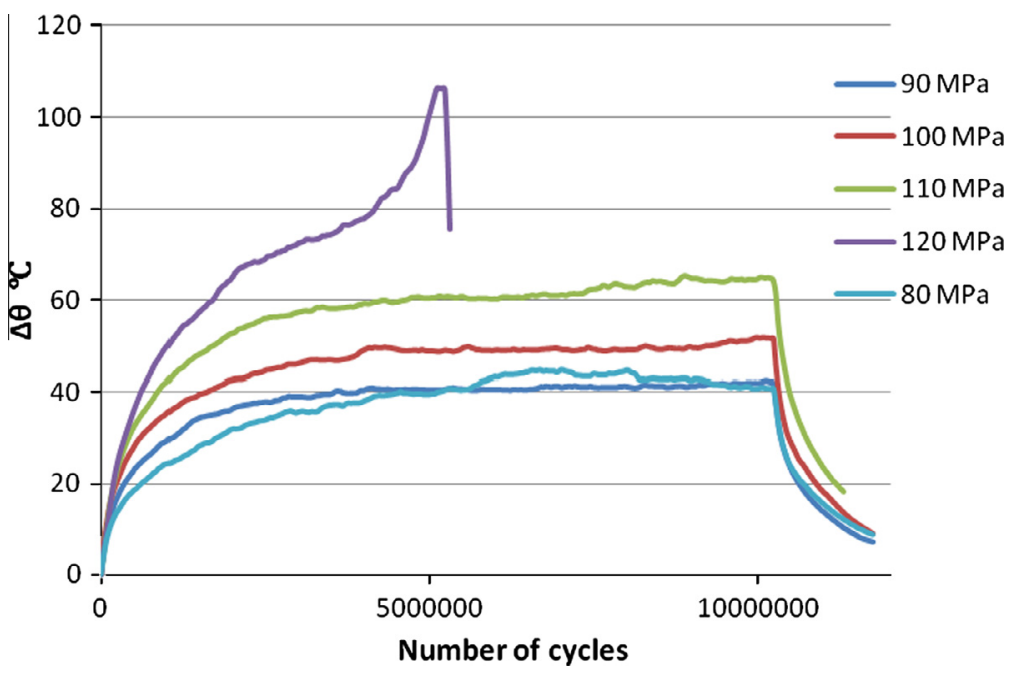

Fig. 3. Temperature evolution versus the number of loading cycles for different stress levels. 


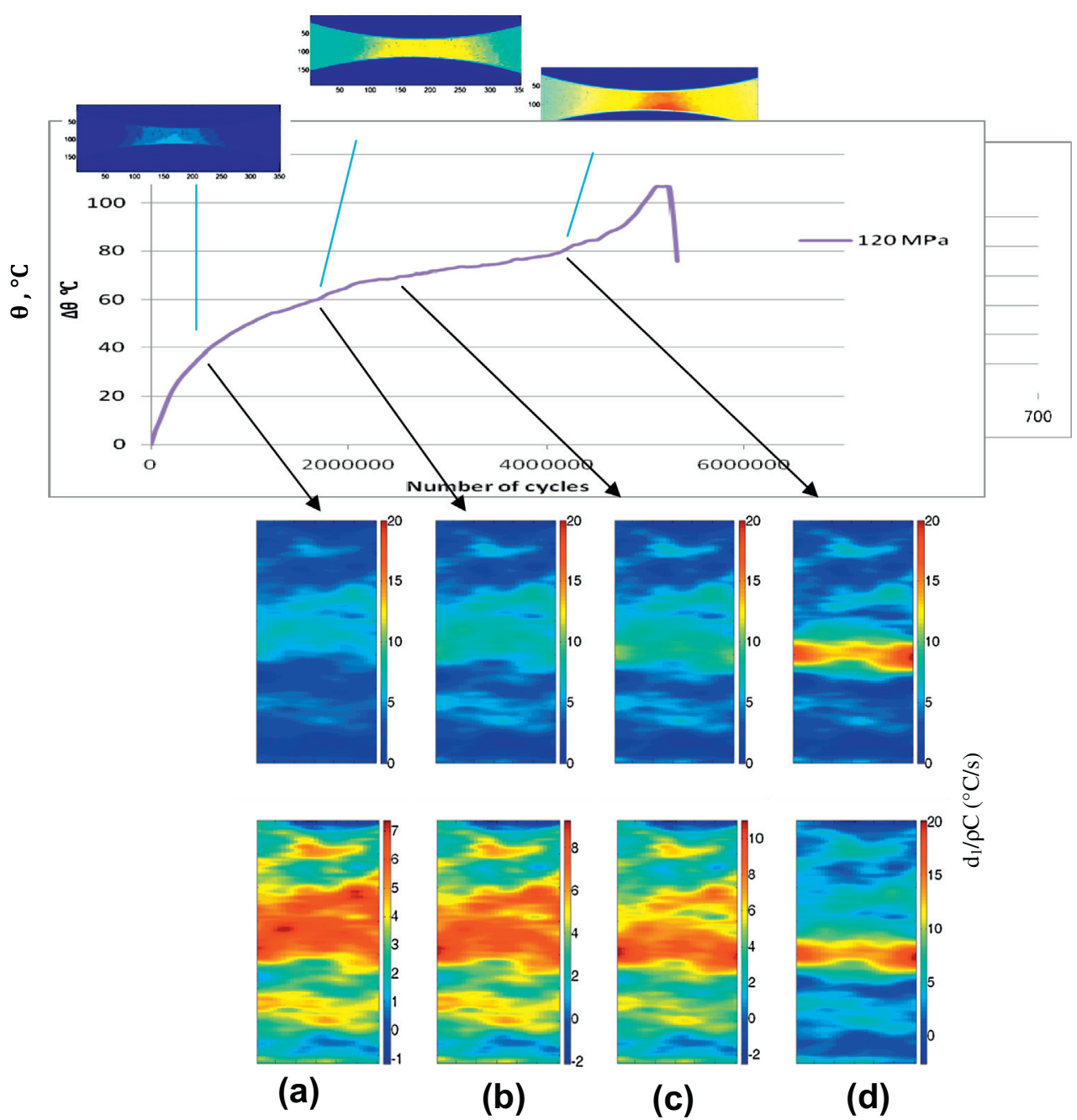

Fig. 5. Infrared thermal images and intrinsic dissipation fields for different numbers of loading cycles.

and the ordinate to the specimen length. At the beginning of the test, the intrinsic dissipation is very low $\left(\sim 5^{\circ} \mathrm{C} / \mathrm{s}\right)$ (Fig. 5a) to reach $20^{\circ} \mathrm{C} / \mathrm{s}$ (Fig. 5d) few seconds before the fracture. In Fig. 5d, the intrinsic dissipation appears higher close to the cross-section in the middle of the specimen, in quite good agreement with the stress concentration along the specimen. The dissipation is lower in a portion located around the middle of the specimen, always in agreement with the stress concentration profile in this cross-section. In Fig. 5d, (cross-section in the middle of the specimen), the intrinsic dissipation is the highest on the right side, which corresponds to the fracture initiation site (see fractographic observations). Note that the intrinsic dissipation is the trace of the specific heat sources in the material subjected to fatigue loading.

\subsection{Fractographic observations}

As is previously reported in the megacycle domain for Armco iron, the first occurrence damage is Slips Marks which are identified as Persistent Slips Bands (PSBs) [7,20]. After removing a thin layer, transgranular microcracks appear just below the PSBs as is shown in Fig. 6a and b.

Sometimes, the first damage occurs in grain boundary. The fracture surface is observed by Scanning Electron Microscope. On the fatigue fracture surface, three areas (Fig. 7a) can be distinguished: stage I, stage I $\rightarrow$ II, stage II.

The stage I corresponds to the initiation stage, and is correlated with the transgranular intrusion/extrusion (Fig. 7b) or intergranular microcracks. When the intrusion/extrusion is transgranular, the grain traces are visible on the fracture surface with "steps" oriented in different directions, steps which are due to PSB and intrusion/extrusion formation. When the microcrack is intergranular, the grain traces are also visible, but the grain surface appears more flat. The stage I $\rightarrow$ II (Fig. 7c) is the beginning of the propagation. In this stage, some striations are visible perpendicular to the direction of crack propagation besides the steps of stage I. The stage II (Fig. 7d) is the crack propagation stage with visible striations perpendicular to the crack propagation direction.

The observation of the polished surface where the temperature variation is recorded shows PSB occurrence over a distance of about $3 \mathrm{~mm}$ (one side) and $3.3 \mathrm{~mm}$ (other side) from the fracture surface. Fig. 8 is a picture just below the fracture surface, where the PSB are present in many grains.

\subsection{Discussion}

The polished surface observed by SEM (Fig. 8) is the surface where the temperature is recorded. The initiation stage (stage I) 
(a)

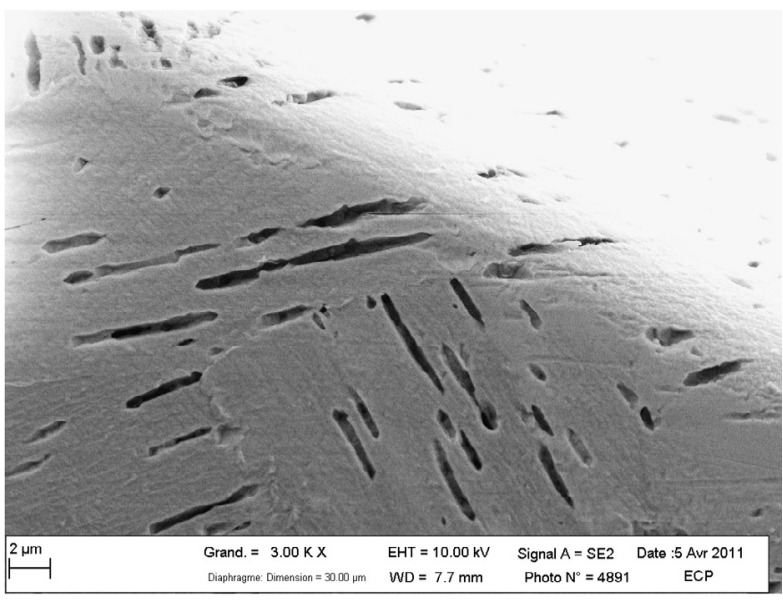

(b)

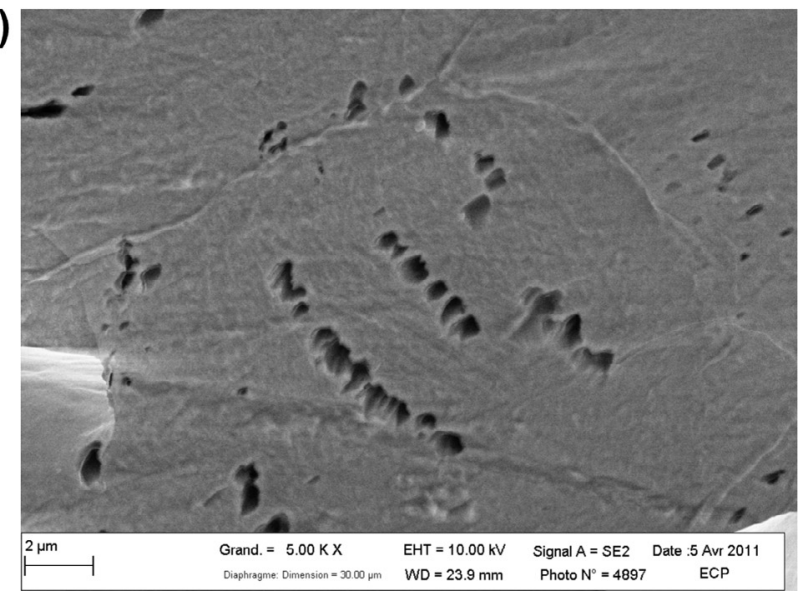

Fig. 6. SEM observation of PSB microstructure at subsurface.

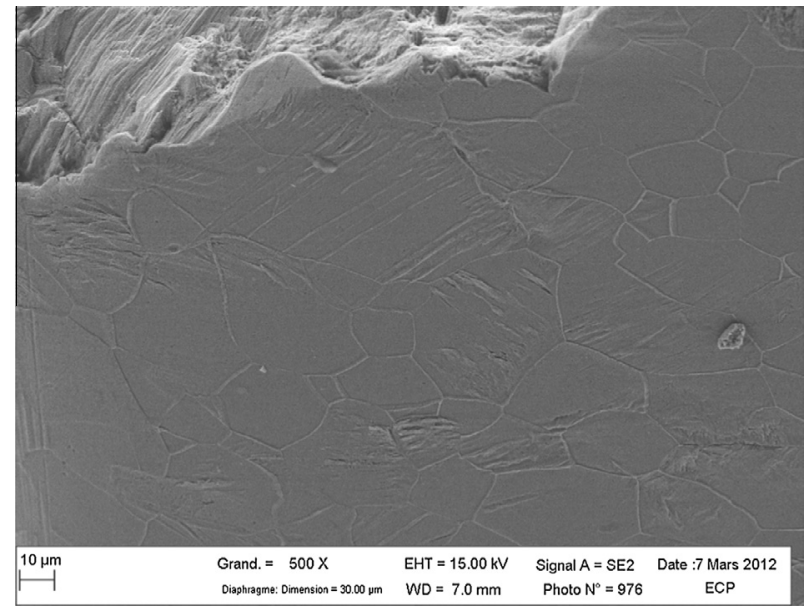

Fig. 8. SEM observation of the polished surface just beneath the crack initiation site.

corresponds to the highest dissipation $d_{1}$ on the right side of last dissipation image seen in Fig. 5. The total length of both sides of fracture surface where PSB occurs is about $6.3 \mathrm{~mm}$, that is to say, in agreement with the area length where $d_{1}$ is the highest $(6 \mathrm{~mm}$ as marks in Fig. 9). White lines indicate axial distance of farthest PSB to the crack section. So, the PSBs are the specific heat sources at the origin of crack initiation (stage I).

If we calculate the effective fatigue stress intensity factor at the end of stage I, $\Delta K_{\text {eff }}=\Delta K_{\mathrm{I}} / 2=3.8 \mathrm{MPa} \sqrt{ } \mathrm{m}$, it is approximately equal to $E \sqrt{ } b=3.4 \mathrm{MPa} \sqrt{ } \mathrm{m}$ for Armco iron (where $E=210 \mathrm{GPa}$ and $b=0.265 \mathrm{~nm}$ ). That is in good agreement with the Herzberg's [21] work about propagation threshold of fatigue crack propagation rate (measured at conventional frequency fatigue test).

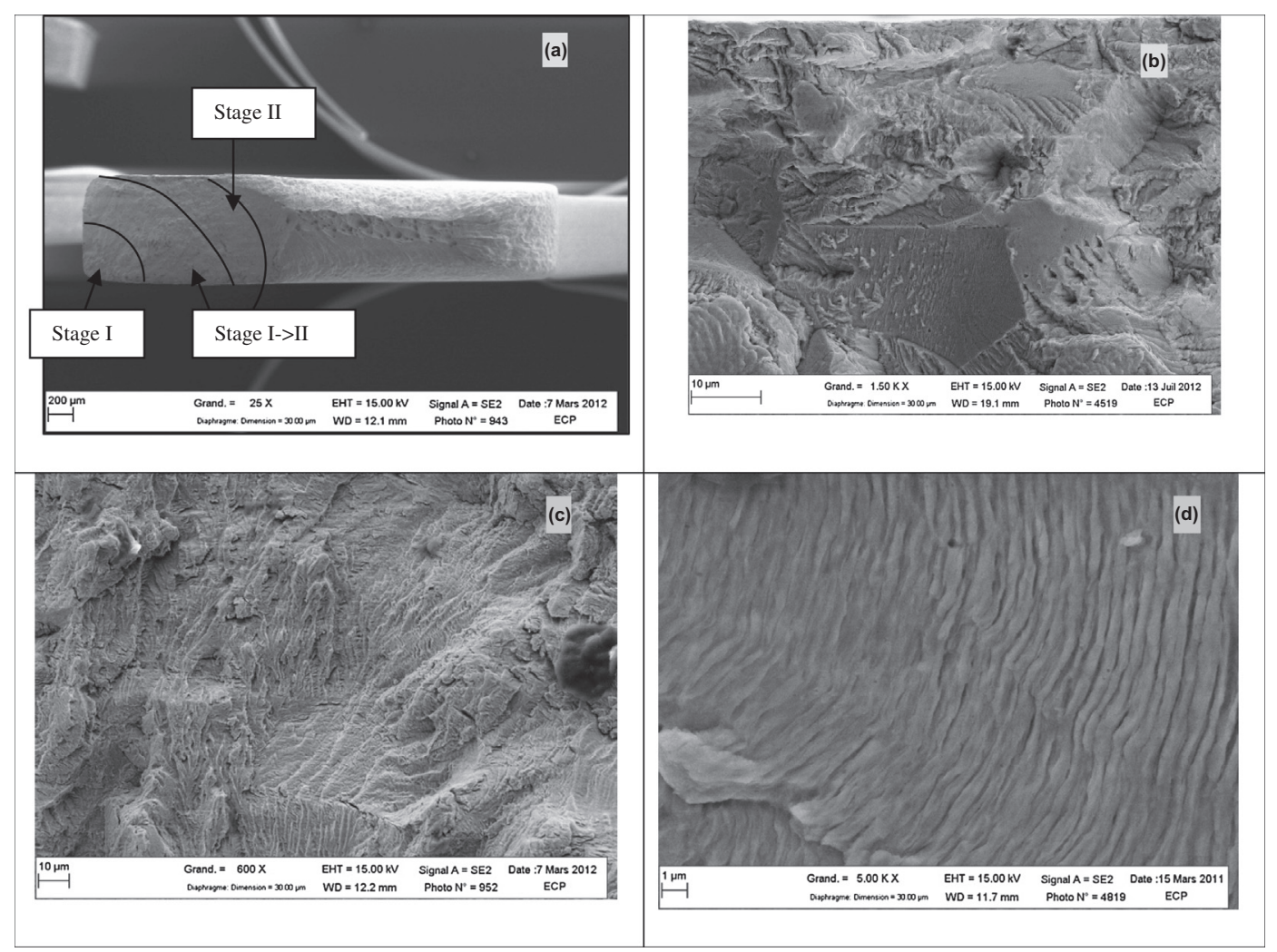

Fig. 7. Fractographic observation of the fracture surface. (a) Fracture surface (b) crack initiation site (stage I) (c) transition stage (stage I $\rightarrow$ II) (d) striation (stage II). 

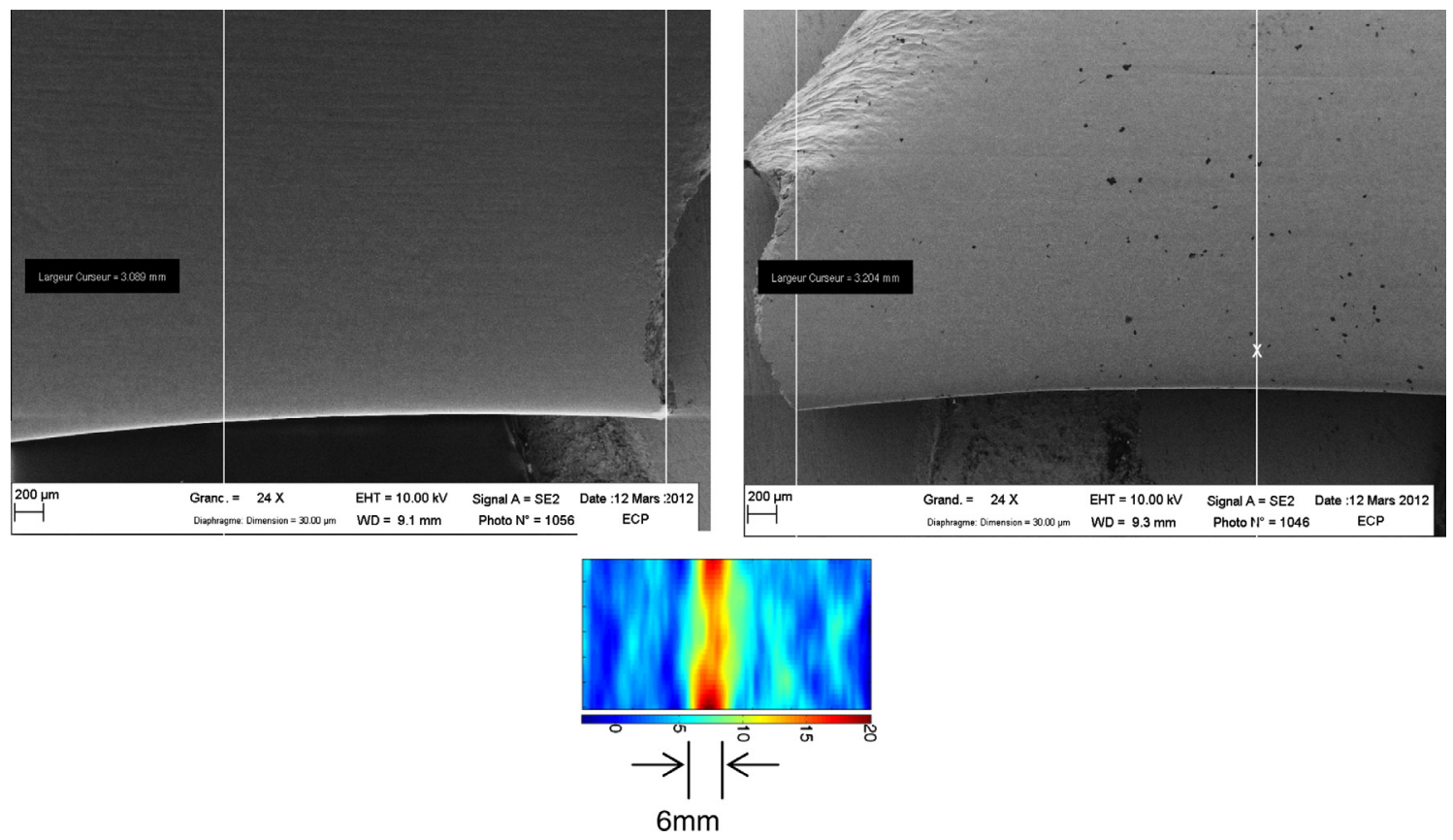

Fig. 9. Correlation between intrinsic dissipation and PSB formation.

\section{Conclusions}

In this study, the first signs of fatigue crack initiation are studied in the HCF domain on a body centered cubic Armco iron (with $80 \mathrm{ppm}$ of carbon content).The tests are performed on a piezoelectric fatigue machine on plate specimens. During fatigue tests, the temperature recorded on the specimen surface allows us to determine the intrinsic dissipation field.

The main conclusions are:

- The localization of higher intrinsic dissipation occurs in the specimen section where the fracture takes place.

- In this section, the dissipation $d_{1}$ is maximum on the specimen right side where the fatigue crack initiation takes place.

- The total length of both sides of fracture surface where PSBs occur in good agreement with the area length where $d_{1}$ takes place. So, the irreversible PSB development induced is correlated to the main energy dissipation sources.

- Fracture surface observations by SEM allow us to precise the crack path during the failure. The initiation stage (stage I) is correlated with the transgranular intrusion/extrusion or intergranular microcracks. At the end of this stage, the calculated $\Delta K_{\text {eff }}=3.8 \mathrm{MPa} \sqrt{ } \mathrm{m}$ is in good agreement with the Herzberg's prediction threshold $(\mathrm{E} \sqrt{ } \mathrm{b}=3.4 \mathrm{MPa} \sqrt{ } \mathrm{m})$. The crack propagation stage (stage II) shows visible striations perpendicular to the crack propagation direction.

\section{Acknowledgements}

This research was supported by the grant from the Project of Microplasticity and energy dissipation in very high cycle Fatigue (DISFAT, Project No. ANR-09-BLAN-0025-09), which was funded by the National Agency of Research, France (ANR).

\section{References}

[1] Suresh S. In: Fatigue of Materials, Cambridge University Press; 2006. p. 37162.

[2] Bathias C, Pineau A. In: Fatigue des matériaux et des structures, vol. 1. Lavoisier; 2008. p. 85-246.

[3] Mughrabi H. In: Haasen P, Gerold V, Kostorz G, editors. The strength of metals and alloys. Oxford: Pergamon Press; 1980. p. 1615-39.

[4] Mughrabi H, Herz K, Stark X. Int J Fract 1976;17:193-320.

[5] Mughrabi H, Wüthrich Ch. Philos Mag 1976;A33:963-84.

[6] Mughrabi H, Ackermann F, Herz K. In: ASTM STP; 1979 675. p. 69-105.

[7] Klesnil M, Lukas P. J Iron Steel Inst 1965;203:1043-8.

[8] Sommer C, Mughrabi H, Lockner D. Acta Mater 1998;46:1527-36.

[9] Wagner D, Ranc N, Bathias C, Paris P. Fat Fract Eng Mater Struct 2009;33:12-21.

[10] Ranc N, Wagner D, Paris PC. Acta Materiala 2008;56:4012-21.

[11] Bathias C, Paris PC. In: Gigacycle fatigue in mechanical practice. New York: Marcel Dekker; 2004. pp 51-76.

[12] Halphen B, Son Nguyen Q. Sur les matériaux standard généralisés. J de Mécanique 1975;14:39-63.

[13] Chrysochoos A, Wattrisse B, Muracciole J-M, El Kaïm Y. Fields of stored energy associated with localized necking of steel. Mech Mater Struct 2009;4(2):245-62.

[14] Pron H, Bissieux C. Focal plane array camera as research tools. Quant Infrared Thermography J 2004;2:229-40.

[15] Batsale JC, Le Niliot C. Estimation de paramètres par thermographie IR Métrologie Thermique et Techniques inverses - 1. Presses Universitaires de Perpignan; 2001 [Chapter 4] 179-236.

[16] Berthel B, Wattrisse B, Chrysochoos A, Galtier A. Thermographic analysis of fatigue dissipation properties of steel sheets. Strain 2007;43(3):273-9.

[17] Berthel B, Chrysochoos A, Wattrisse B, Galtier A. Infrared image processing for the calorimetric analysis of fatigue phenomena. Exp Mech 2008;48: 79-90.

[18] Boulanger T, Chrysochoos A, Mabru C, Galtier A. Calorimetric analysis of dissipative and thermoelastic effects associated with the fatigue behavior of steels. Int J Fatigue 2004;26(3):221-9.

[19] Doudard C, Calloch S, Hild F, Roux S. Identification of heat source fields from infra-red thermography: determination of 'self-heating' in a dual-phase steel by using a dog bone sample. Mech Mater 2010;42:55-62.

[20] Wang C, Wagner D, Wang QY, Bathias C. Int J Fatigue 2012;45 December: 91-7.

[21] Paris PC, Tada H, Keith Donald J. Int J Fatigue 1999;21:35-46. 